\title{
“两性一度” 背景下《酒店前厅与客房管理》金课建设路径探讨
}

唐靖雯

洛阳理工学院经济与管理学院

DOI:10.32629/er.v3i4.2675

[摘 要] 教育部吴岩司长提出 “两性一度” 的 “金课” 标准。本文根据 “两性一度” 的要求,分别从课堂讲授内容、课堂教学方法、期末成绩 评定方式等三方面,探讨《酒店前厅与客房管理》课程的金课建设路径。

[关键词] 酒店前厅与客房管理；金课；两性一度

2018年6月21日召开的中国高等学校本科教育工作会议上, 教育部部 长陈宝生向全国教师号召：消灭 “水课”, 建设 “金课”。教育部高等教育 司司长吴岩提出了金课的标准一一 “两性一度”, 即高阶性、创新性、挑 战度。

“两性一度”, 即高阶性、创新性、挑战度。所谓 “高阶性”, 是指知 识能力素养的有机融合, 培养学生具有解决各种复杂问题的综合素质以及 高级思维。所谓 “创新性”, 是指课程内容要能反映出前沿性和时代性, 在教学形式上要呈现出先进性和互动性, 学习成果则具有探究性、鲜明的 个性化。而所谓 “挑战度”, 指的是课程需要有一定难度, 需要学习者跳一 下才能抓住重点, 对老师课程的准备、学生课下练习有较高要求。与此相 反, “水课” 则是指低阶性、陈旧性和无心敷衍的课。

在 “两性一度” 的背景下, 作者就自己主讲的《酒店前厅与客房管理》 课程从课堂讲授内容、课堂教学方法、期末成绩评定方式三方面进行思考。

\section{1 传统课堂《酒店前厅与客房管理》中存在的问题分析}

1. 1课程教材缺乏实用性

酒店管理专业在笔者所在学院是新上的本科专业, 根据《酒店管理》 本科教学大纲的要求, 本科专业课程必须选用相对应的本科教材。该专业 属于新兴专业, 市面上的教材很多都是从16年开始出版, 并且还没有出现 具有行业权威或者经典性的教材; 有些主编老师缺乏酒店实际从业经验, 教材的实用性不强。

之前本门课程笔者选用的教材《前厅与客房管理》, 书中内容全面, 但是缺乏案例支撑, 书中关于 “超额预订” 公式的信息都出现失误; 教材 里面提到的一些知识点比较老, 与现代酒店行业的操作流程有些不符合等 等; 广西师范大学出版的教材《客房服务与管理》、《前厅运行与管理》, 教材中内容排版合理, 案例多, 但是却是将前厅、客房这两个部门分别出的 教材, 不能合二为一。

1.2 专业课教师更新行业知识较慢

酒店管理专业的《酒店前厅与客房管理》从 2016-1017学年开课伊始, 到现在已经第七年了, 由于这是一门新设置的专业, 酒店管理专业所属的 学院近几年一直致力于该专业的管理与改进, 以期将该专业与酒店行业更 好的衔接, 以培育出更多符合酒店业需要的优秀人才。本人作为该课程的 老师, 在进入学校上班之前, 曾经就职于某五星级酒店, 积累了前厅与客房 服务的工作经验。近几年酒店行业发展迅速, 对客服务标准也出现变化, 本人从进入学校以后有将近 5 年没有机会参与到酒店一线的工作, 对于酒 店业的了解一般都是从网络、书籍中了解到, 酒店行业知识更新较慢。

\section{3 课堂教学方法因循守旧}

《酒店前厅与客房管理》遵循传统的课堂授课方式, 以老师为中心, 讲解为主, 学生被动的接受课堂知识, 缺乏学习积极性。学生课前不预习, 课后不复习, 课堂上的案例讨论缺乏热情。
1. 4课程考核方式不能体现应用性

笔者所在的学校为应用型本科院校。《酒店前厅与客房管理》这门课 程的期末成绩分别由平时成绩和考试成绩组成, 两者的比例分别为 $20 \%$ 和 $80 \%$ 。该门课程是所涉及的是酒店的两个关键部门: 前厅和客房, 知识应用 性极强。因此, 这种由平时成绩与期末考试成绩 $2: 8$ 的评分方式, 忽略了课 程的应用性强的特点, 限制了学生学习积极性。

\section{2 《酒店前厅与客房管理》“金课”建设路径建议}

2.1改革课堂讲授内容, 展现课程的高阶性

《酒店前厅与客房管理》属于酒店管理专业的核心专业课, 但是笔 者通过近几年的积累的教学经验以及外出学习, 通过对比发现, 该门课 程存在定位不合理、内容更新慢、与酒店管理专业其他课程存在部门重 合等内容。

在 “金课” 建设中, 改革授课内容上, 应从以下几个方面着手:

2.1.1授课内容的选择上集众家之所长, 不局限于某一本教材

本校近几年处于教学改革阶段, 教学大纲经常变化, 最近两年还在改 革阶段。这种变化对于教学有一定不良的影响。

因此, 经过与本课程企业指导老师的反复探讨, 认为该课程的授课内 容不以单一的教材内容为主, 而是结合各教材之所长, 充实授课计划中的 学习内容。在以唐飞主编, 重庆大学出版社出版《前厅与客房管理》的为 教材的基础上, 每个章节的内容都从不同的教材中找到内容翔实、适合同 学们学习的知识点。例如: 酒店前厅的销售部分, 则主要以刘伟主编的, 中国旅游出版社出版的《酒店前厅与客房部运行与管理》中的 “客房销售 技巧” 为主; “客房安全” 的章节内容, 则主要参考马勇主编, 华中科技大 学出版的《酒店客房服务与管理》中的 “客房安全管理的章节”。不同的 教材, 知识的侧重点不一样, 集各教材之所长, 充实授课内容, 提升本门课 程的授课质量, 丰富同学们关于酒店前厅与客服的基础知识。

2.1.2吸收酒店专业知识的渠道多样化

在教材上下功夫的同时, 笔者认为还应该通过酒店方面的专业论文以 及网站来寻找与本课程有关的资料。万豪酒店集团旗下致力于中国酒店教 育发展的慈善项目 “万礼豪程” 项目的网站, 提供了酒店教学各方面的真 实视频, 以及通过为酒店业教师提供挂职机会而收集而来的各类案例, 为 笔者的课堂教学提供了丰富的资料。洲际、香格里拉等国际知名酒店集团 的公众号关注, 其中推送的一些文章, 让笔者有机会接触到酒店行业的最 新动态。酒店前厅部的一个重要任务是客房销售, 在讲授这一内容时, 从酒 店前厅服务员的销售技巧开始, 进而讲解到了现在各酒店集团为了吸引客 人推出的VIP会员制, 以某城市浦香的会员制营销为例, 在详细介绍了酒店 会员制的内容后, 引导同学们用所学知识来分析上海浦香会员制的利弊。这 些会员制的知识来源, 是通过网络获得的。

2.1.3校企合作, 授课内容紧跟当今酒店发展潮流 
在传统教材的基础上, 课堂上应增加酒店目前正在使用的一些新的方 面的知识。例如: 酒店智能化、酒店互联网销售渠道分析等。这些新的知 识, 都是教材中提及却未展开的一些内容, 增加这些酒店发展的最新内容, 可以帮助同学们在酒店顶岗实习时更好的融入酒店的工作环境。

2. 2改善课堂教学方法, 体现课堂的创新性

改善授课方法的关键, 是将课堂上以老师为中心, 转变成以学生为 中心。

\subsection{1调动学生的学习积极性}

在课堂上, 教师的身份变成课堂的引导者、参与者, 学生则变成课堂的 中心, 成为课堂的主动学习者、发现者。教师根据学生的兴趣, 引导其在本 门课程的学习, 共同完成本门课程教学任务。

在具体的教学中, 老师的主要任务是带领同学们阅读大量的课外资 料, 例如经典的教材、论文等, 每次上课前确定一个课程主体, 布置任务, 学生分组完成任务。在课堂上老师占用较少时间简单讲解知识点, 其余 时间则让同学们参与案例讨论或者播放本组同学共同完成的PPT。新的 授课方法, 将学生学习知识, 资料收集安排中课堂以外的时间, 课堂上主 要是展示自己学习的心得, 老师与同学们中课堂上完成思想的交流以及 知识的探讨。

2.2.2 利用新的教学工具, 提升课堂的智能化

第一, 在教学中习惯性的使用英文酒店专业术语。同学们的酒店顶岗 实习, 选择的基本上都是国际知名酒店集团旗下的高星级酒店, 这些酒店 前台使用的是OPERA操作系统, 全英文页面, 并且在酒店工作中, 很多专业 术语也是用英文。这与同学们平时的生活、学习习惯有很大的不同; 同学 们平时接触英文少, 初到陌生的酒店, 环境的改变, 中文到英文的思维切换, 让同学们或多或少会有压力。因此, 在平时的教学中, 多跟同学们用英文沟 通; 或者是在说到一些酒店专业术语时, 用英语表达, 有助于同学们适应外 资酒店的工作环境。第二, 使用学习通教学, 学习渠道多元化。对于《酒店 前厅与客房管理》部分内容进行学习通的教学, 课前教师通过PPT等方式 让同学们对知识点进行了解, 提出问题, 学生课前学习; 课堂上主要解决 同学们认为理解困难的知识点。学习通的时候, 有利于增加老师与同学 们互动, 也方便同学们在课外进行预习和复习, 提升同学们的学习能力 以及思考能力。

2.3改良期末成绩评定方式, 提升课程挑战性

《酒店前厅与客房管理》课程之前期末闭卷考试成绩占据课程总成绩
的比重高 $(80 \%)$, 期末成绩评定方式以试卷类考试为主, 俗称闭卷考试。尽 管学生考试前都会花时间复习, 但是班级里大多数学生考分不高, 主观题 回答很难拿高分。说明学生的专业知识功底不扎实, 平时对于课程知识的 复习时间少, 对于主观题的分析不到位, 导致考试成绩不理想。

2.3. 1 关注成绩的评定过程, 评定标准细化

根据建设应用型本科的要求, 课程考核要以学生职业能力培养为核心, 因此, 本课程应进行考核方式改革。建议学生最终考核成绩分别由平时成 绩 (20\%), 课程内实验成绩 (20\%), 闭卷考试成绩 (60\%)。平时成绩中, 考勤以 教学手册记录为依据, 课堂表现和学习态度根据课堂发言讨论及笔记记录 情况, 作业完成情况根据作业完成质量评定成绩; 学生课堂表现由以下几 个方面判定: 是否遵守课堂纪律、课堂上是否积极配合老师的教学活动、 能否认真准备课堂讨论的资料等; 作业则是每章节结束后, 会布置相关内 容的案例分析, 可以及时检查学生关于章节内容的掌握情况。课程内实训 成绩, 根据学生课堂实训表现实训报告成绩评定; 考试成绩则是最后的闭 卷考试的内容, 试卷由老师根据授课内容决定, 考核内容则是本学期课程 专业知识的 $80 \%$, 题型分别为客观题和主观题组成, 主观题所占据的分数较 高, 可以更好的考察学生的知识综合运用能力。

2. 3. 2理解并熟练使用课程基本知识, 增强课程学习效果

本课程作为专业核心课程, 根据学校要求, 要进行试卷类考核。试卷出 题范围以书本上的理论知识为基础, 包含了该课程中参考的教材、著作等, 但是却没有建立本课程的试题库。试题库中各类知识点的学习以选择题和 判断题为主, 每种题型的题量至少 100 个左右, 以方便学生网上做题练习。 学生通过试题库中刷题, 找出自己本课程学习中的薄弱环节, 并通过做题 将薄弱环节提升, 力争将每个知识点理解并且熟练使用, 提升专业素养。

\section{[参考文献]}

[1]吴岩.建设中国“金课”[J].中国大学教学,2018(12):12-14.

[2]王艳茹.大学 “金课” 的智慧教学法——原理、内涵与框架设计 [J]. 创新与创业教育,2018(05):28-31.

[3]段莎,卫强. “金课” 背景下翻转课堂教学的实施探究——《管理 会计》课程为例 []].现代工贸商业,2018(05):77-79.

\section{作者简介:}

唐靖雯(1982--), 女,汉族,广西桂林人,讲师,硕士研究生,主要从事 旅游经济研究。 